\title{
Special Education without Teaching Assistants? The Development Process for Students with Autism
}

\author{
Irene Rämä ${ }^{1}$, Elina Kontu ${ }^{2} \&$ Raija Pirttimaa ${ }^{3}$ \\ ${ }^{1}$ Researcher, $\mathrm{PhD}$ (Education), University of Helsinki, Faculty of Educational Sciences, Centre for Educational \\ Assessment, Finland \\ ${ }^{2}$ Adjunct Professor, PhD (Education), University of Helsinki, Faculty of Educational Sciences, Finland \\ ${ }^{3}$ Professor, PhD (Education), University of Jyväskylä, Faculty of Education and Psychology, Finland \\ Correspondence: Irene Rämä, Verkkotie 19, 00980 Helsinki, Finland. E-mail: irene.rama@helsinki.fi
}

Received: September 26, 2019 Accepted: November 2, 2020 Online Published: November 26, 2020

doi:10.5539/jel.v9n6p163 URL: https://doi.org/10.5539/jel.v9n6p163

\begin{abstract}
Many children may need the help of another person to attend school. It is common for children with disabilities to receive help from a teaching assistant at school. Assistants are provided in many countries as a legal right and are often publicly funded. It is also widely assumed that having teaching assistants in the class is an effective and cost-efficient way to support students with disabilities. In this study, the research task was to monitor and document the development process carried out by the teacher, with the aim of making visible the development of a more dynamic classroom interaction. The focus in this development process was the teacher's idea of minimizing the contacts between students and assistants to increase students' opportunities to optimize interaction and learning. This was to happen by strengthening commitment to their activities and taking responsibility. The data include video excerpts, which originate from video recordings from a special education class, and transcripts of three stimulated recall-type interviews with the teacher of this class. In this article, the experimental development process is described as presenting an unorthodox approach to teaching assistants and their position in special education.
\end{abstract}

Keywords: special education, teaching assistant, communication, interaction, development process

\section{Introduction}

\subsection{The Role of Teacher Assistants}

Many children may need the help of another person to attend school. It is common for children with disabilities to receive help from a teaching assistant at school. School assistants, interpreters, students' personal assistants, and teachers' assistants or instructors working alongside teachers are provided in many countries as a legal right and often publicly funded (see Legislation Updates, 2017; Special Needs Education in Europe, 2006). With inclusion, assistants, school tutors, and other student support staff are more often working in regular classrooms with the teachers (Takala, 2007). The titles of people working alongside teachers vary and they include descriptors such as assistants, school helpers, teacher or education aides, school instructors, personal helpers/assistants, paraprofessionals, paraeducators, teacher assistants, teaching assistants, and learning support assistants or officers. In this article, we have used the term teaching assistants in most cases because it most clearly describes the perspective of our article.

The number of teaching assistants has grown in many countries (Radford, Bosanquet, Webster, Blatchford, \& Rubie-Davis, 2014; Giangreco \& Doyle, 2007). One-to-one assisting is typical, especially if a student is diagnosed with having an intellectual disability (Giangreco, 2010). In Finland, only three per cent of all schools did not hire teaching assistants (Kumpulainen, 2014, p. 69).

Although the roles and tasks of a teaching assistant can vary widely between schools and countries (Maher \& Vickerman, 2017), there are common features. The duties usually include assisting a student in certain matters, such as self-care and pedagogical tasks; the implementation of various arrangements (e.g., preparing the classroom for teaching), and further supporting the teacher (e.g., with the production of material) (Rubie-Davies, Blatchford, Webster, Koutsoubou, \& Basset, 2010; Takala, 2007). The work is practical, say teaching assistants (Maher \& Vickerman, 2017), and they consider encouraging the child to be one of their important tasks (Lindqvist, Nilholm, 
Almqvist, \& Wetsoa, 2011). It is also widely assumed that having teaching assistants in the class is an effective and cost-efficient way to support students with disabilities (Harris \& Aprile, 2015; O’Rourke \& West, 2015).

Helping students to stay focused and follow instructions is also one of the tasks (Symes \& Humphrey, 2011). During the school day, assistants may not always have an opportunity to work with teachers, and the work of assistants may be poorly planned or managed (Symes \& Humphrey, 2011; Takala, 2007). Takala (2007) found that teaching assistants often just sat next to their assigned students and listened to the teacher. Researchers of autism who observed classrooms (Azad, Locke, Downey, Xie, \& Mandell, 2015) also discovered that teaching assistants used just over half of their time to guide or support a student (57 per cent of their time). A valuable resource is therefore inefficiently used.

A great deal of trust is placed in teaching assistants, and they may be considered necessary for successful, high-quality teaching. That said, there are also objections. For example, based on various studies Giangreco (2010) claimed that the teaching assistant issue has not been adequately studied. Giangreco (2010) also presented a list of potential problems that may be caused by the work of teaching assistants: Students with teaching assistants may not develop usual relationships with other students and students may be stigmatized and even bullied. Moreover, a close relationship with a teaching assistant may result in a student losing control of his or her own affairs and an over-dependence on the teaching assistant. In their literature review, Giangreco, Suter and Doyle (2010) reported on studies that found a student can also become dependent on a teaching assistant's style of instruction, contact with the teacher may be disturbed, and behavioural problems may occur.

As the closest person to the student, a teaching assistant often serves as a mediator or liaison between the student and the teacher and other students (Chopra \& French, 2004). Issues relating to attentiveness, communication, and behaviour control may be left to the teaching assistant, which raises the question of whether teaching assistants have adequate training for these duties (Martin \& Alborz, 2014; Carter, Stephenson, \& Webster, 2018). Brown, Farrington, Ziegler, Knight and Ross (1999) are worried that to assign the lowest paid, least qualified, and often inadequately supervised paraprofessionals to assist with instructional activities for the students with the most complex learning characteristics.

Rubie-Davies and colleagues (Rubie-Davies et al., 2010) elaborated on classroom roles: Teachers' work seems to focus on learning and comprehension, while teaching assistants focus on the completion of tasks or even completing tasks on behalf students. Radford, Blatchford and Webster (2011) claimed that teachers generally 'open up' the students, whereas teaching assistants 'close down' the discussions with students they assist. However, the teaching assistants created a relaxed and comfortable atmosphere when working with students (Rubie-Davies et al., 2010). Students may have a closer relationship with their assistants than their teachers, which may be due to the assistants' belief that the direct communication between them and the students is the right way to communicate. The assistants were also confident about their own abilities to deal with the students (Paju, Räty, Pirttimaa, \& Kontu, 2015). Although the classroom roles seem to be different, teachers should ensure that teaching assistants succeed in their support (Howes, 2009). When students have been asked about their opinions on teaching assistants, appreciation has been noted, and children consider teaching assistants to be important, reliable adults. Students have said they especially like nice, warm, caring, and understanding teaching assistants (Bland \& Sleightholme, 2012).

\subsection{Autism Spectrum Disorder}

Autism Spectrum Disorder (ASD) is a neurodevelopmental disorder characterized by persistent impairment in reciprocal social communication and social interaction (American Psychiatric Association, APA, 2013). The challenges regarding communication and social interaction was the argument for choosing this focus group as a target in the development process: All learning is based on flexible interaction between the learner and his or her environment including other people and this requires spontaneous, expressive communication (Chiang \& Carter, 2008). Hence, the deficits linked to ASD considerably disrupt learning. The ASD also exhibits restricted and repetitive patterns regarding behaviour, interests, and activities (APA, 2013), all of which also have an effect on interaction. Different hyper or hypo sensitivities occur, and difficulties in transitions and preferring established routines. Exceptionally good memorizing, enthusiasm and knowledge regarding certain interests, original thinking and a unique way to visual thinking can be taken as strengths of those with ASD (See e.g., APA, 2013, pp. 50-59; Baron-Cohen, 2008; Baron-Cohen \& Belmonte, 2005; Bogdashina, 2005; Frith, 2003; Happé, 1994; Courchesne, Townsend, \& Saitoh, 1994; World Health Organization, WHO, 2010; Wing, 1992).

\subsection{Research Task}

The main idea of our research based on informal conversations with an experienced special education teacher, who was not satisfied with the interaction in her special education class. The class comprised six students with ASD: 
Every student also had a personal teaching assistant. The original concern of the teacher regarding the interaction in the class was that even if there was considerable interactional action in the class, the interaction was not desirable regarding the relations between the students, personal teaching assistants and the teacher (Rämä \& Kontu, 2012, p. 418). It seems that the quality of the interaction followed the suggestions the researchers made (Giangreco, 2010): The students were monitoring personal teaching assistants, not their peers or the teacher's speech/talk. The teacher felt that there were intermediaries (personal teacher assistants) between her and the students. The situation hampered her pedagogical activities

Initially, in our study we aimed to describe the activities and events in one classroom, mainly from the perspective of interaction in general. However, the teacher's observations and remarks about the classroom activities were interesting. Thus, we began to follow her systematic search for change that focused on teaching and the division of labour between her and the assistants. The teacher's insightful, pedagogical experimental process transformed the direction of the process of observation and description into a research-oriented direction. The task of the research was to monitor and document the development process carried out by the teacher, with the aim of making visible the development of a more dynamic classroom interaction.

\section{Data and Analysis}

This article describes the development process of one special education class in a Finnish comprehensive school. The section reported here consist of descriptions of the study participants, data collecting procedure and the method the data were analysed. The development process focused to the interaction between the teacher, the students and the personal teaching assistants in this very same class.

\subsection{Participants}

The special education class examined comprised six male students, of whom four began their studies in the same year. The others joined the class later. All students had a diagnosis of with Autism Spectrum Disorder (ASD) and were about seven years old at the beginning of the development process (2006). Every student also had a personal teaching assistant; this tells us something about the severity of the features of their ASD. However, the students did not have significant sensory impairments with regard to sight or hearing and they had no mobility problems. The same combination of students continued in the class throughout the study, and the same qualified special education teacher with over 20 years of experience took responsibility for the students throughout their school years.

\subsection{Data}

The study consisted of two types of data. The first set of data included video excerpts, which originated from video recordings recorded in the previously mentioned special education class. The video recordings were collected by ISE research group at University of Helsinki, Finland, and were recorded in authentic classroom situations (years 2006-2009). About 8 hours video recordings, which include morning meetings (morning circles), lessons with subject teaching/learning and assessment situations, were available for this study. Video data collecting procedure is presented in Figure 1. 


\section{VIDEO RECORDINGS (ISE Research Group)}

Collection of video recordings recorded in authentic special education teaching sessions in a class comprising students with autism spectrum disorder. Subject lessons, morning meetings (circles), and student assessment situations were included. With or without the assistants. Totally about 110 hours, recorded in years 2006-2009.

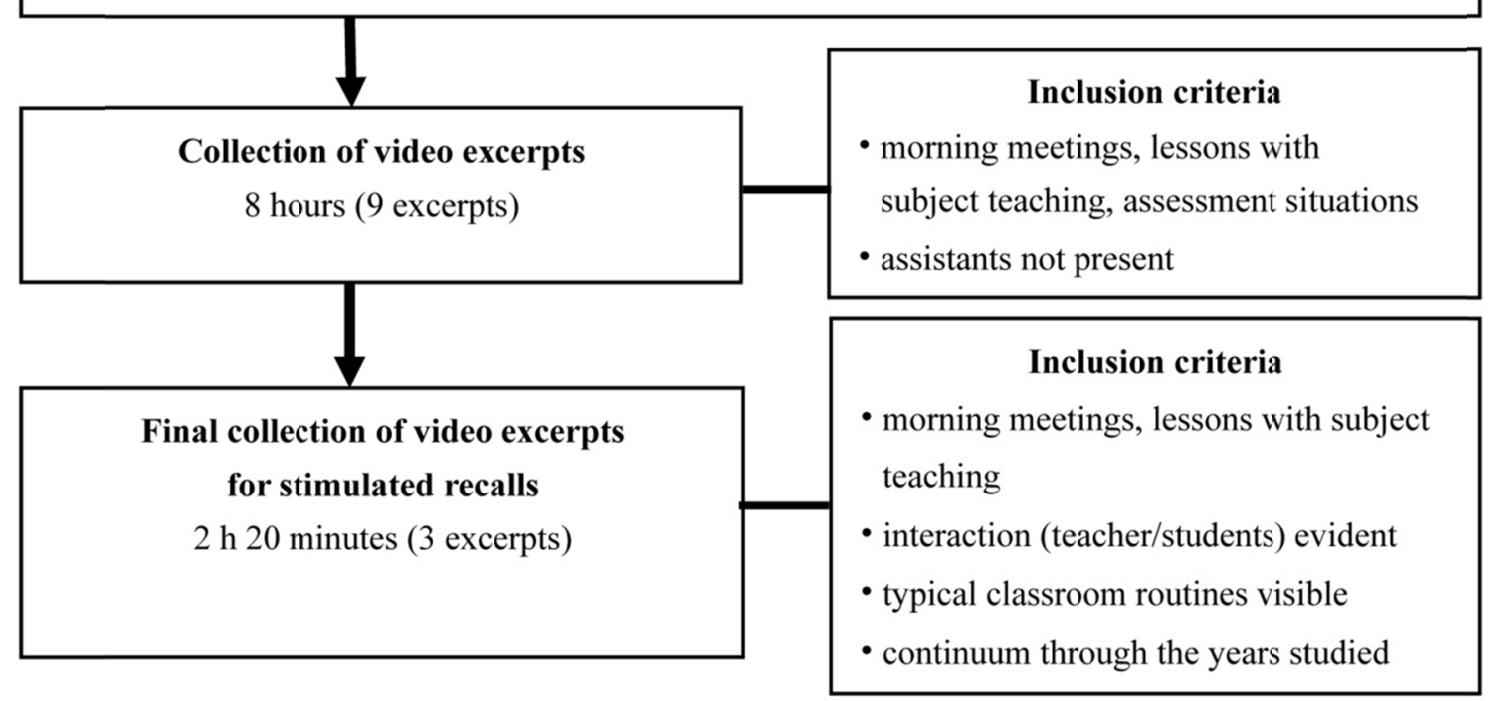

Figure 1. Video data collection procedure in short. The arrows show the path to the final data.

The other data source consisted of the transcripts of the stimulated recall-type interviews with the teacher of this class (stimulated recall, see Patrikainen \& Toom, 2004). The interviews also had features used in elite interviews (Harvey, 2011). This interview method was chosen to make the teacher's hidden intervention visible. The interviewee is an experienced pedagogue and qualified special education teacher, who has participated in and conducted manifold development processes during her career. She has worked for many years as a teacher but also as a head of school. She had decision-making power and experience in putting many school reforms into practice at school, municipality and state levels. The types of the interviews are presented in Table 1 .

Table 1. Interviews

\begin{tabular}{lllll}
\hline & Timespan & Type & Duration & Participants \\
\hline Interview 1 & $12 / 2006$ & Face-to-face & $19 \mathrm{~min}$ & teacher \\
Interview 2 & $9 / 2009$ & Face-to-face & $58 \mathrm{~min}$ & teacher \\
Interview 3 & $1 / 2019$ & On the phone & $15 \mathrm{~min}$ & teacher \\
Interview 4 & $11 / 2011$ & Face-to-face & $24 \mathrm{~min}$ & teacher, assistant \\
\hline
\end{tabular}

Note. Interviews 1 and 2 were linked to stimulated recalls, interview 3 was a follow-up, and interview 4 was made to get a description from the assistant perspective.

\subsection{Analysis}

For the study, the video data were delved into thoroughly to detect excerpts that could be used in the interviews. The time span for the video recordings was three years from 2006 to 2009. There were nine video recordings totalling eight hours of which 140 minutes were used for the interviews. The essential criteria for choosing certain excerpts were that the excerpts were from typical classroom situations, in which typical routines were visible, the teaching assistants were not present, and the interaction between the teacher and the students was evident. It was also important that the situations in the excerpts represented a continuum through the years.

The teacher was interviewed three times (in 2006 and 2009 face-to-face, and 2019 on the phone). The first two interviews were stimulated recall interviews in which the interviews were based on those previously recorded 
tapes. The interviews were based mainly on morning meetings, because those situations remained constant over the years and most of the video recordings consisted of those meetings. The interviewer and the interviewee discussed excerpts picked up from the video recordings while the interviewer was guiding the conversation with thematic questions on the interactional situations seen on the recordings. The themes of conversations focused on the role of teaching assistants, the aspects of the behaviour changes of the students, and the changes in the relationships between the teacher and the students and between the students.

The phases of developmental process and the arguments for the direction and the changes of the process that emerged in the teacher interviews were combined with the video recordings made in authentic teaching sessions in the class. Hence, the big picture of the development process was made as a combination of the interviews and video recordings.

\section{Description of the Development Process}

The description of the development process is divided in three parts. First, we delineate between the situation prevailing in the classroom before anything was done to improve the learning background, it is the interaction (see Chapter 3.1). Then we describe the first attempt to change the situation in the classroom by increasing the proximity (see Chapter 3.2). After that, we give an account of the second phase of the process (see Chapter 3.3) which focuses on the students' interactional and participational activation.

\subsection{First Observations of the Classroom Activities}

The first observations of the classroom activities supported our impression that teaching and interaction proceeded smoothly during the morning meetings. There were few disruptions and the meetings moved along as planned but the teacher saw the situation differently:

And I think I could not teach those students if I was far from them, like at the morning meeting, when I am alone with the students; that's the way I have get closer to the students, I have learnt to know them better. (TH06/1:5; RV1/4)

If I were in front of the class and the assistants were besides the students and they do what I tell them to do, I think it doesn't work out. (TH06/1:6; RV3/3)

Moreover, the teacher pointed out that there were few interactions between the students, if any at all. This is easily observed in the video recordings as well (e.g., video recordings in 2006). This observation surprised the teacher, because the point of these morning meetings was to provide the students with orientation and, most importantly, to generate opportunities for having mutual experiences and sharing between the participants. Instead, most of the interaction took place between students and their personal teaching assistant. The teacher also mentioned in the interview that she gave the teaching assistants commissions, which could be interpreted as making the assistants responsible for individualising the instruction (TH19/1:3). According to the teacher, she felt being left alone at the front of the class (TH06/1:6). However, increasing the active participation of students and facilitating/enhancing their independent initiatives and independence is stressed in the National Core Curriculum for Basic Education (FNAE 2014). Hence, the instruction should develop the student's skills and also make the participation possible. The situation in the classroom studied clearly differed from the content expressed in official documents and acts (e.g., FNAE 2014; Basic Education Act 1998/2010).

\subsection{The First Phase: Increasing the Proximity Between the Teacher and the Students}

The teacher told that it took almost a year to decide to reduce the role of the teaching assistants in the classroom, especially during the morning meetings (TH19/1:1). When she went for it, the first step was to reduce activities with the personal teaching assistants to see what changes might happen in classroom interaction. All the personal teaching assistants were instructed to withdraw physically from their students. Still, the assistants remained nearby in case something unexpected should happen and help was needed. This type of situation is seen in the video recording recorded in 2006 (video excerpt VN06/B]. However, the procedure described above had not been planned with the assistants but the teacher simply felt that she noticed more accurately the individual needs for adjusting the teaching for certain students (TH19/1:4). At the beginning of this phase, a single assistant might have stayed beside a student and helped them focus on an activity or keep in place during class. This situation is seen, for example, in the video excerpt VN07/24.

Because of this adjustment, interactions between the students and the teacher increased, and the teacher noticed that the interactions between some students seemed to increase as well. This was exactly what the teacher had thought would happen, and what she had hoped for, but from the teaching assistants' points of view, their jobs now included more waiting and acting as backup, which was frustrating for them (see also Takala, 2007). 
...[when] the personal assistant is as far away as possible, behind [her/his student], it means waiting time for the assistant (TH06/1:4a; RV1/2). As well the assistants understand, well, when we have discussed it [the deeper meaning of their withdrawal] (TH06/1:4b; RV1/3)

However, the teaching assistants were still needed, although the teacher's actions were also regarded as her aim was to show that she managed without the help of the assistants (TH06/1:4c). The assistants were also responsible for the actions during the moments before and after the actual school day; hence they have many other tasks and duties. The teacher made sure that the assistants were conscious of the goals of the development process: I have explained to them [to the assistants] that it is not important what we produce but the social goals... (TH06/1:4d). Since the morning meetings proceeded without continuous assistance, it was sensible for the personal teaching assistants to do something useful during the morning meetings. For example, the assistant might prepare a student's individual learning materials. The need for individual materials is constant in special education and it is challenging to find the time to plan and prepare materials. According to Kokko and her colleagues (2013), Finnish special education teachers could use only three per cent of their working hours to prepare learning materials.

\subsection{The Second Phase: Strengthening the Relationships Between the Students, and Systematically Reinforcing the Active Participation of the Students}

Even at this point of the process, the teacher was not satisfied with these behavioural changes, so she again called for more qualitative modifications to interaction and communication. In this final phase of the process, the teacher decided to focus on the interactions between the students. She instructed the personal teaching assistants to leave the classroom completely. This was an unorthodox way to proceed in the context of special education in Finland: Especially with students who have personal teaching assistants in question, compared to classrooms with so-called 'general assistants' who help any student needing support. Although the personal teaching assistants had left the classroom, they were close enough to be reached if necessary; for example, they were in the next room.

Moreover, the teacher modified her teaching and communicative style during the morning meetings. She changed her traditional teacher-centred style towards supporting the students through more participatory activities. For example, she stepped aside to avoid standing alone in front of the class, stopped delivering her pedagogical monologues and encouraged the students to contribute to moving the morning meeting along. The teacher selected one student at a time to lead a certain routine. The routine could include choosing the music for the meeting, naming the day of the week, defining the right time of the year or the weather, checking out the daily schedule and so on (an example of a morning meeting routine can be seen in video excerpt VN09/06). If the student needed support or did not know what to do, the teacher helped and instructed him. Other students had opportunities to help as well.

As a result of this process, interactions and communication increased in the classroom, both between the teacher and the students and amongst the students themselves. The interactions were more animated, and the teacher felt she could better reach the students without the assistance of go-betweens such as the personal teaching assistants. The increase in interactions amongst peers can be observed when comparing video recordings from the beginning of the process to the latest video recordings. As the teacher concluded:

I think, grouping. I don't know if it possible to say. Even Eric, from one meter's distance. Who doesn't show any external signs of belonging to the group, he clearly seemed to follow [the situation]. (TH06/1:7; RV2/2)

And Joel. Quite different [type], obviously a member. And Joel and James began to help Oscar, who didn't know what should be done, and corrected him, when he was wrong, like no, no, no, no, not that way. (TH06/1:8d; RV3/3)

Or for example, now, when Oscar doesn't have a communicator of his own ..., so that, when Joel and Oscar use a shared communicator: when Joel has written his own [writings], he brings it [the communicator] to Oscar. (TH06/1:9; RV3/4, RV2/4)

Moreover, the students were communicating in a more spontaneous nature. This was further confirmed by analysing their communication through Carter and Hotchkis's framework (Rämä, Kontu, \& Pirttimaa, 2014). In conversations that were linked to out-of-school activities, like an excursion to an amusement park, the students were clearly excited and initiated lots of spontaneous interactions and commented on each other's statements (Rämä et al. 2014). (Video excerpt VN05/2008).

However, not everybody at the school was excited about the process but thought that the process was about egotism. Still, the teacher who started this experiment tried to clarify its meaning and purpose/intent to the other teachers and apparently partly succeeded in that.

Yes, they ... what I'm trying to show, that I'll manage without the [teaching] assistants (TH06/1:4c) 
The assistants understand, well, when we talk about the matter... (TH06/1:4b)

The observations the teacher made on the presence and development of socialization were tangible and sensitive. The teacher's enthusiasm and interest in the students' changing behaviour encouraged her to hold to the new arrangements at the morning meetings.

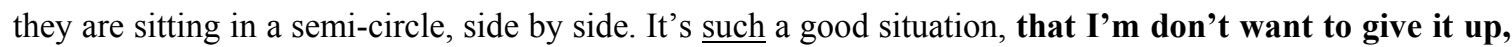
not in any case. All the time there's fussing and harassing. They are physically like so near to each other. It takes place suddenly; someone puts their arm on someone else's, and it might happen that this other guy doesn't tolerate this [hug] at all. And pushes the arm off. Or gingerly puts up with the arm. And I'm there feeling, Yess! Super; now he made it that way! (TH06/1:9; RV3/4, RV2/4)

\section{Discussion}

The aim of the study took shape as a follow-up and a documentation of the developmental process the teacher accomplished. The goal of this process was to make visible the more dynamic classroom interaction along the process. The most important change the teacher made was linked to the actions of the personal teaching assistants: direct contact between the students and the assistants were minimized during the morning meetings. With this change, the teacher consciously facilitated her students' opportunities to commit to their activities and to take responsibility, while helping the students manage these activities. She did not leave the students on their own, but neither did she do everything for them. The teacher encouraged the students to join the group, made space for communication and expressions of the students' own wills and let them act spontaneously such as messing up or fiddling around. The students also had opportunities for co-operating with each other, demonstrating their knowledge and being autonomous.

It is possible to conceptualize the teacher's experiment demonstrating the development process focused on changing the interaction between the participants in the classroom by using Alan Fogel's (1993) theory of mutual co-regulation. According to Fogel, the educational situation is considered to be an interactional process that consists of dynamic transactions between the participants. The participants dynamically alter their interactional actions with respect to the ongoing or anticipated actions of their partners. This kind of co-regulation also takes the student's inner world and motivation firmly into consideration. For example, this is seen in the teacher's development process in the absence of teaching assistants and due to that, the change in the teacher's actions forces or facilitates the student to search for a prompt from somewhere else which is seen in student's communicative initiatives (Rämä, 2015).

In general, interactional flexibility is a precondition for successful communication. That is, participants must be able to adjust their communication dynamically in different situations. This has often been considered to be a challenge in educating children with autism, which sometimes leads to the use of communication that is too simplistic. Although establishing a structure is considered to be important for people with ASD, highly structured environments are not recommended: it would be more sensible to educate or foster students with ASD in the ways that allow them to pursue more natural means of interaction and communication. If possible, there is a preference for educating them without the use of intermediaries like personal teaching assistants.

To be clear, we are not suggesting that personal teaching assistants are unnecessary, but it may be worthwhile to reconsider the content of their jobs. Teaching assistants should not encourage students to become too dependent, but these assistants should rather support the the students' communication, develop their abilities to make and maintain friendships, and help them live as autonomously as possible in their communities. If we accept the notion that the teacher has the pedagogical leadership in the classroom, it would be desirable for them to be skilled enough to instruct the other adults working in the same classroom. School-based staff training might be useful (Walker \& Smith, 2015) but teachers or schools should be trained for it.

Teaching assistants can be an important part of classroom interaction and provide meaningful support for the teacher and the students but their usefulness depends on how prepared they are professionally. In the case of ASD, disorder characteristics place certain prerequisites for teacher assistants to ensure flexible and skilled activity in the classroom. Persistent impairment in social interaction and communication is one of the key features in ASD. In general, teacher assistants should be aware of the challenges students experience in their everyday life, especially regarding social interaction, and assistants should be acquainted with the support available to help students to overcome these challenges. Hence, teacher assistants should have adequate in-service training to understand the basic principles of augmentative and alternative communication (AAC), and of how to guide students to use appropriate AAC-methods efficiently. A typical feature of students with ASD are restricted and repetitive patterns regarding behaviour, interests, and activities, which hamper and delay learning. Teacher assistants have an important role in helping students back to the learning mode but the detection of these 
situations calls for sensitive observation. Preventing frustration rising from dissatisfactory communication is another skill needed when supporting students with ASD, as frustration can burst out with offensive or aggressive actions, which are not desirable in the classroom and hinder learning. Teacher and teacher assistants should work together with convergent goals and a shared conception of students' characteristics. Adults should co-operate and negotiate constantly to keep their common information up-to-date.

The virtue of this article is that it describes the development process of one special education professional in the framework of intensive special support. The article provides information that could be utilised when enhancing teachers' know-how in different educational contexts, for example, when developing or supporting teachers' pedagogical leadership skills for instruction that is executed with students and several adults.

\section{References}

American Psychiatric Association (APA). (2013). Diagnostic and Statistical Manual of Mental Disorders: $D S M-5^{T M}$. Washington, DC: American Psychiatric Association. https://doi.org/10.1176/appi.books.9780890425596

Azad, G. F., Locke, J., Downey, M. M., Xie, M., \& Mandell, D. S. (2015). One-to-One Assistant Engagement in Autism Support Classrooms. Teacher Education and Special Education, 38(4), 337-346. https://doi.org/10.1177/0888406415603208

Baron-Cohen, S. (2008). Autism and Asperger Syndrome. Oxford: Oxford University Press.

Baron-Cohen, S., \& Belmonte, M. K. (2005). Autism: A Window onto the Development of the Social and the Analytic Brain. Annual Review of Neuroscience, 28, 109-126. https://doi.org/10.1146/annurev.neuro.27.070203.144137

Basic Education Act. (1998/2010). Special-needs support. [Perusopetuslaki 1998/2010. Erityinen tuki §17] Retrieved March 23, 2019, from https://www.finlex.fi/en/laki/kaannokset/1998/en19980628.pdf

Bland, K., \& Sleightholme, S. (2012). Researching the Pupil Voice: What Makes a Good Teaching Assistant? Support for Learning, 27(4), 172-176. https://doi.org/10.1111/1467-9604.12000

Bogdashina, O. (2005). Communication Issues in Autism and Asperger Syndrome. London: Jessica Kingsley.

Brown, L., Farrington, K., Knight, T., Ross, C., \& Ziegler, M. (1999). Fewer Paraprofessionals and More Teachers and Therapists in Educational Programs for Students with Significant Disabilities. Journal of the Association for Persons with Severe Handicaps, 24, 250-253. https://doi.org/10.2511/rpsd.24.4.250

Carter, M., Stephenson, J., \& Webster, A. (2018). A Survey of Professional Tasks and Training Needs of Teaching Assistants in New South Wales Mainstream Public Schools. Journal of Intellectual \& Developmental Disability, 44(4), 447-456. https://doi.org/10.3109/13668250.2018.1462638

Chopra, R. V., \& French, N. K. (2004). Paraeducator Relationships with Parents of Students with Significant Disabilities. Remedial and Special Education, 25, 240-251. https://doi.org/10.1177/07419325040250040701

Courchesne, E., Townsend, J., \& Saitoh, O. (1994). The Brain in Infantile Autism: Posterior Fossa Structures Are Abnormal. Neurology, 44, 214-223. https://doi.org/10.1212/WNL.44.2.214

Finnish National Agency for Education (FNAE). (2014). The core curriculum for basic education 2014. Retrieved from http://www.oph.fi/english/curricula_and_qualifications/basic_education/curricula_2014

Fogel, A. (1993). Developing through relationships: Origins of communication, self, and culture. New York, NY: Harvester/Wheatsheaf.

Frith, U. (2003). Autism: Explaining the enigma. Malden, MA: Blackwell.

Giangreco, M. F. (2010). One-to-one Paraprofessionals for Students with Disabilities in Inclusive Classrooms: Is Conventional Wisdom Wrong? Intellectual and Developmental Disabilities, 48(1), 1-13. https://doi.org/10.1352/1934-9556-48.1.1

Giangreco, M. F., \& Doyle, M. B. (2007). Teacher Assistants in Inclusive Schools. In L. Florian (Ed.), The SAGE Handbook of Special Education (pp. 429-439). London: Sage.

Giangreco, M. F., Suter, J. C., \& Doyle, M. B. (2010). Paraprofessionals in Inclusive Schools: A Review of Recent Research. Journal of Educational and Psychological Consultation, 20(1), 41-57. https://doi.org/10.1080/10474410903535356

Happé, F. (1994). Autism - An Introduction to Psychological Theory. London: UCL Press. 
Harris, L. R., \& Aprile, K. T. (2015). “I can sort a slot into many different roles": Examining Teacher Aide Roles and Their Implications for Practice. School Leadership \& Management, 35(2), 140-162. https://doi.org/10.1080/13632434.2014.992774

Harvey, W. S. (2011). Strategies for Conducting Elite Interviews. Qualitative Research, 11(4), 431-441. https://doi.org/10.1177/1468794111404329

Howes, A. (2003). Teaching Reforms and the Impact of Paid Adult Support on Participation and Learning in Mainstream Schools. Support for Learning, 18, 147-153. https://doi.org/10.1046/j.0268-2141.2003.00300.x

Kumpulainen, T. (Ed.). (2014). The Statistical Yearbook of Education 2014. Finnish National Agency for Education. Helsinki. Retrieved from https://www.oph.fi/sites/default/files/documents/koulutuksen-tilastollinen-vuosikirja-2014.pdf

Legislation Updates. (2017). European Agency for Special Needs and Inclusive Education. Retrieved from https://www.european-agency.org/sites/default/files/Legislation\%20Updates\%202017.pdf

Lindqvist, G., Nilholm, C., Almqvist, L., \& Wetsoa, G.-M. (2011). Different Agendas? The Views of Different Occupational Groups on Special Needs Education. European Journal of Special Needs Education, 26(2), 143-157. https://doi.org/10.1080/08856257.2011.563604

Maher, A. J., \& Vickerman, P. (2017). Ideology Influencing Action: Special Educational Needs Co-ordinator and Learning Support Assistant Role Conceptualisations and Experiences of Special Needs Education in England. Journal of Research in Special Educational Needs, 18(1), 15-24. https://doi.org/10.1111/1471-3802.12389

Martin, T., \& Alborz, A. (2014). Supporting the Education of Pupils with Profound Intellectual and Multiple Disabilities: The Views of Teaching Assistants Regarding Their Own Learning and Development Needs. British Journal of Special Education, 41(3), 309-327. https://doi.org/10.1111/1467-8578.12070

O'Rourke, J., \& West, J. (2015). Education Assistant Support in Inclusive Western Australian Classrooms: Trialling a Screening Tool in an Australian Context. International Journal of Disability, Development and Education, 62, 531-546. https://doi.org/10.1080/1034912X.2015.1052376

Paju, B., Räty, L., Pirttimaa, R., \& Kontu, E. (2015). The School Staff's Perception of Their Ability to Teach Special Educational Needs Pupils in Inclusive Settings in Finland. International Journal of Inclusive Education, 20(8), 801-815. https://doi.org/10.1080/13603116.2015.1074731

Patrikainen, S., \& Toom, A. (2004). Stimulated recall—A Method to Study Teacher's Pedagogical Thinking and Action. In P. Kansanen \& K. Uusikylä (Eds.), The various methods of research on teaching (pp. 239-260). Jyväskylä: PS-kustannus.

Radford, J., Blatchford, P., \& Webster, R. (2011). Opening Up and Closing Down: How Teachers and TAs Manage Turn-taking, Topic and Repair in Mathematics Lessons. Learning and Instruction, 21, 625-635. https://doi.org/10.1016/j.learninstruc.2011.01.004

Radford, J., Bosanquet, P., Webster, R., Blatchford, P., \& Rubie-Davis, C. (2014). Fostering Learner Independence through Heuristic Scaffolding: A Valuable Role for Teaching Assistant. International Journal of Educational Research, 63, 116-126. https://doi.org/10.1016/j.ijer.2013.02.010

Rämä, I. (2015). Negotiated together: Examining the classroom interaction of students with ASD. Doctoral thesis. University of Helsinki. Research report 377.

Rämä, I., \& Kontu, E. (2012). Searching for Pedagogical Adaptations by Exploring Teacher's Tacit Knowledge and Interactional Co-regulation in the Education of Pupils with Autism. European Journal of Special Needs Education, 27(4), 417-431. https://doi.org/10.1080/08856257.2012.701064

Ramberg, J., Lénárt, A., \& Watkins, A. (Eds.). (2018). EASIE. European Agency Statistics on Inclusive Education: 2016 Dataset Cross-Country Report. Retrieved May 22, 2019, from https://www.european-agency.org/resources/publications/european-agency-statistics-inclusive-education-20 16-dataset-cross-country

Rubie-Davies, C., Blatchford, P., Webster, R., Koutsoubou, M., \& Bassett, P. (2010). Enhancing Learning? A Comparison of Teacher and Teaching Assistant Interactions with Pupils. School Effectiveness and School Improvement, 21(4), 429-449. https://doi.org/10.1080/09243453.2010.512800

Special Needs Education in Europe. (2006). Provision in Post-primary Education (vol. 2). Thematic Publication. Retrieved from https://www.european-agency.org/sites/default/files/special-needs-education-in-europe-volume-2-provision 
-in-post-primary-education_Thematic-EN.pdf

Statistics Finland. (2018). Increasingly more comprehensive school pupils received intensified or special support. Retrieved from https://www.stat.fi/til/erop/2017/erop_2017_2018-06-11_tie_001_en.html

Symes, W., \& Humphrey, N. (2011). The Deployment, Training and Teacher Relationships of Teaching Assistants Supporting Pupils with Autistic Spectrum Disorders (ASD) in Mainstream Secondary Schools. British Journal of Special Education, 38(2), 57-64. https://doi.org/10.1111/j.1467-8578.2011.00499.x

Takala, M. (2007). The Work of Classroom Assistant in Special and Mainstream Education in Finland. British Journal of Special Education, 34(1), 50-57. https://doi.org/10.1111/j.1467-8578.2007.00453.x

Walker, V. L., \& Smith, C. G. (2015). Training Paraprofessionals to Support Students with Disabilities: A Literature Review. Exceptionality, 23(3), 170-191.https://doi.org/10.1080/09362835.2014.986606

Wing, L. (1992). The Triad of Impairments of Social Interaction: An Aid to Diagnosis. London: National Autistic Society.

World Health Organization (WHO). (2010). International Statistical Classification of Diseases and Related Health Problems (ICD-10). Retrieved from http://apps.who.int/classifications/icd10/browse/2010/en

\section{Copyrights}

Copyright for this article is retained by the author, with first publication rights granted to the journal.

This is an open-access article distributed under the terms and conditions of the Creative Commons Attribution license (http://creativecommons.org/licenses/by/4.0/). 